\title{
Comparison of Shape Memory Staple and Gelled Platelet-Rich Plasma versus Shape Memory Staple alone for the Treatment of Waist Scaphoid Nonunion: A Single-Center Experience
}

\author{
Rocco De Vitis ${ }^{1,2, *(i)}$ Marco Passiatore ${ }^{1, *(1)}$ Andrea Perna ${ }^{1(1)}$ Giulio Fioravanti Cinci ${ }^{1(0)}$ \\ Giuseppe Taccardo ${ }^{1,20}$ \\ ${ }^{1}$ Istituto di Clinica Ortopedica, Fondazione Policlinico Universitario A. \\ Gemelli IRCCS, Rome, Italy \\ 2 Università Cattolica del Sacro Cuore, Rome, Italy \\ Address for correspondence Andrea Perna, MD, Istituto di Clinica \\ Ortopedica, Fondazione Policlinico Universitario A. Gemelli IRCCS, \\ Rome 000168, Italy (e-mail: perna.andrea90@gmail.com).
} Joints 2019;7:84-90.

\begin{abstract}
Purpose The aim of this study was to analyze the results of two different methods of surgical treatment of waist scaphoid nonunions (SNUs). We retrospectively analyzed data from 87 patients referred to our department from January 2010 to December 2017 who were surgically treated for waist SNU.

Methods The mean period of time passed from trauma was $11.2( \pm 5.6)$ months. Patients were divided into two groups based on surgical treatment received: volar exposure osteosynthesis with shape memory staple (SMS) (group A) and volar exposure osteosynthesis with SMS and gelled platelet-rich plasma (GPRP) application at the bone defect level (group B). A cast (thumb excluded) was maintained for 4 weeks. Healing was checked clinically (pain, QuickDASH [Disabilities of the Arm, Shoulder, and Hand] score, Mayo Wrist Score) and radiologically (standard X-ray).

\section{Keywords}

- scaphoid

- staple

- scaphoid nonunion

- shape memory staple

- platelet-rich plasma

Results Union was achieved in 40 patients in group A (95.2\%) and in all patients in group B (45 patients; $100 \%$ ). A statistically significant difference was observed in the improvement of the Mayo Wrist Score, QuickDASH score, and pain (measured through the visual analog scale) after 3 months from surgery $(p=0.02)$.

Conclusion SMS is effective in treating waist SNU at more than 6 months from trauma. GPRP application can improve bone healing and upper limb function.

Level of Evidence This is a retrospective observational Level III study.
\end{abstract}

\section{Introduction}

Fracture of the scaphoid bone is one of the most common fractures of the carpus. ${ }^{1,2}$ Scaphoid bone heals by direct ossification due to the lack of periosteal covering; therefore, the whole blood arrives to the fracture from the intraosseous vascularity. ${ }^{3}$ The reported incidence of nonunion for scaphoid fractures is approxi-

* These authors contributed equally to the study.

received

June 4, 2019

accepted

April 4, 2020

published online

May 6, 2020 mately 5 to $10 \%{ }^{4}$ Scaphoid fractures frequently displace, depending on the directions of the forces and on the kind of fracture, and this worsens the already weak healing capacity. ${ }^{5}$ Nonunion can be painful and, if left untreated, often leads to osteoarthritis. ${ }^{5}$ Scaphoid nonunions (SNUs) always require surgery. ${ }^{6}$ Many techniques that require bone graft have been suggested. ${ }^{6,7}$

The biological activity of platelet-rich plasma (PRP) on bone healing has been described. ${ }^{8-10}$ The use of PRP in delayed unions and nonunions has already been investigated. ${ }^{10}$ There

\footnotetext{
(c) 2020. The Author(s).

This is an open access article published by Thieme under the terms of the Creative Commons Attribution-NonDerivative-NonCommercial-License, permitting copying and reproduction so long as the original work is given appropriate credit. Contents may not be used for commercial purposes, or adapted, remixed, transformed or built upon. (https://creativecommons.org/ licenses/by-nc-nd/4.0/) Georg Thieme Verlag KG, Rüdigerstraße 14, 70469 Stuttgart, Germany
} 
is no consensus on the benefit of PRP apposition in fracture healing. ${ }^{11}$ Evidence on the use of PRP in SNU is still lacking, ${ }^{12}$ although its application has been already investigated applied on a bone graft. ${ }^{13}$ The aim of the study was to investigate the role of gelled PRP (GPRP) in patients with SNU (later than 6 months from fracture diagnosis or fracture occurrence) treated surgically with staple osteosynthesis, without bone autograft.

\section{Methods}

\section{Study Design and Setting}

This is a single-center observational retrospective analysis performed at our Hand Surgery Unit from January 2010 to December 2017. The study matches national ethics criteria and is in accordance with the Helsinki convention. Considering that the study techniques were the gold standard for the treatment of SNU classified as type D without shortening and without humpback deformity (according to the Herbert classification ${ }^{14}$ ) in our institution, a formal ethical approval was not needed for this retrospective study. All patients provided a written informed consent before the surgery.

\section{Inclusion and Exclusion Criteria}

All adult (skeletally mature patients aged 19 years or older) patients with a unilateral waist SNU type D (according to the Herbert classification ${ }^{14}$ ) for more than 6 months from diagnosis, with good radiological dataset (standard X-ray preoperative, postoperative X-ray at 1, 2, 3, 6 and 12 months, and preoperative computed tomography [CT] scan) and at least one1year follow-up, were eligible for the study.

We excluded from the study patients with the following:

- Proximal pole SNU.

- Displacement gap $>2 \mathrm{~mm}$ with shortening of the scaphoid (severe bone loss and severe shortening), as calculated on a CT scan.

- Humpback deformity.

- Perilunate fracture-dislocation.

- Dorsal intercalated segmental instability.

- SNU Advanced Collapse(SNAC) injury stages 2, 3, and 4 . $^{15}$

- Previous trauma and/or surgical treatment on the treated hand.

- Less than 6 months passed from the trauma clearly referable to the fracture.

\section{Treatment}

The enrolled patients were divided into the following two groups based on the received treatment: osteosynthesis with shape memory staple (SMS) (group A) and osteosynthesis with SMS and GPRP application at the bone defect level (group B). All patients were treated by a single surgical team comprising two senior hand surgeons (G. T. and R. D. V.). A volar approach to the scaphoid was used. The radial artery and the palmar cutaneous branch of the median nerve were identified and protected. Volar radiocarpal capsulotomy was performed, and the radiolunate and radioscaphocapitate ligaments were dissected. The nonunion was exposed. An accurate debridement was performed using nonpowered tools: a gentle curettage of the surfaces of fracture was performed, and the fibrous tissue interposed (if present) was completely excised. Two holes were made into each bone fragment to allow the accommodation of the staple. Before being applied, the staple is adapted in desired width. Then it is forcibly inserted into the holes. This kind of staple compressed the bone fragments by heating with body heat ${ }^{16}$ and it holds the correct length of the bone and it prevents rotations of poles.

In group B patients, the bone gap was filled with GPRP. A sample of peripheral blood was used to prepare GPRP according to the protocol described in - Fig. 1. After production, the GPRP was immediately administered. It has the consistency and appearance of a gelatinous compound that could be gently applied to fill the gap (-Fig. 2).

GPRP is gently inserted in the gap using forceps: approximately 0.05 up to $0.1 \mathrm{~cm}^{3}$ of GPRP are necessary to completely fill the gap. Finally, the capsule is sutured over, providing an additional protection, to avoid its leakage.

\section{GPRP preparation}
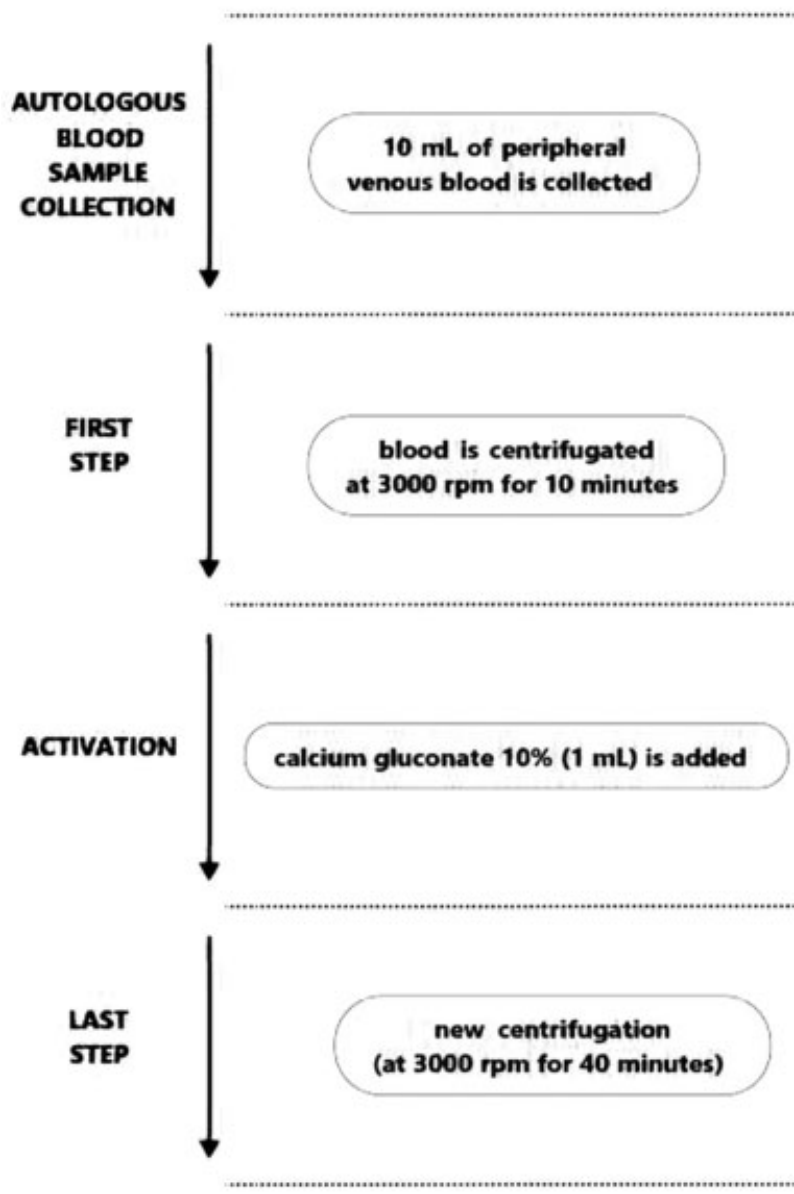

\section{gelatinous substrate is obtained}

Fig. 1 Production of gelled platelet-rich plasma. 


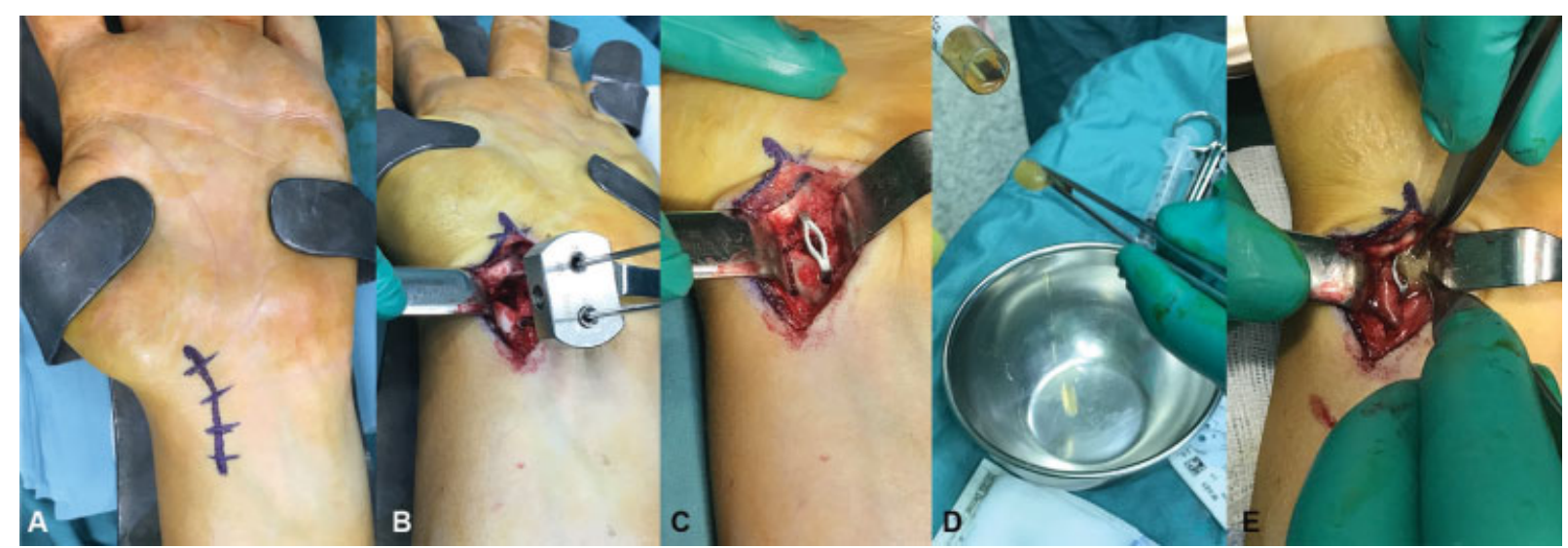

Fig. 2 Surgical treatment. (A) Surgical exposure. (B) Debridement at the nonunion site is performed. Two K-wires are inserted to allow the accommodation of the staple. (C) The staple fixes the bone. (D) Autologous gelled platelet-rich plasma (GPRP) is identified with a label. (E) GPRP is gently inserted to fill the gap.

All patients were immobilized in a short-arm cast excluding the thumb for 4 weeks. They were reviewed through serial outpatient checks, as described previously, according to institutional protocols.

\section{Outcomes}

The primary outcome of the study was the union assessment. Scaphoid union was defined as consolidation in plain radiograph associated with the absence of clinical findings (e.g., snuffbox compression pain, spontaneous pain, pain at wrist motion) and a visual analog scale (VAS) score of $<4$. The secondary outcome was to assess the improvement of hand and wrist function and pain, the rate of complication and surgical failure.

During recruiting, plain radiographs in semipronated oblique, anteroposterior, and lateral views were obtained for all patients. Every recruited patient underwent a CT examination of the affected wrist prior to surgical treatment for surgical planning. A careful assessment of the scaphoid length and deformity was performed. The radiographic results were evaluated through plain radiographs obtained at $1,2,3,6$, and 12 months after surgery.

The findings for the assessment of union have been already reported previously.

Postoperative CT was performed at least 3 months after surgery to confirm radiological healing (presence of bone bridges between the two fragments) in patients with uncertain healing (nondiscriminatory radiographs associated with persistence of pain symptoms). The functional improvement and the clinical success of the surgery were evaluated using the QuickDASH (Disabilities of the Arm, Shoulder, and Hand) score and Mayo Wrist Score (MWS) before surgical treatment, and after 3, 6, and 12 months. Pain was evaluated using a 10-item VAS before the surgery, and after 3, 6, and 12 months.

\section{Statistical Analysis}

All data are presented as mean and standard deviation. Only one decimal digit was reported (rounded up). Student's $t$-test was used to compare parametric data. For nonparametric data, Mann-Whitney's $U$ test was used. The significance was established for a value of $p<0.05$. All statistical analyses were performed using the SPPS statistical calculation software (SPSS Inc., Chicago, Illinois, United States).

\section{Results}

A total of 87 (17 females, 70 males) patients met the inclusion criteria and had a good radiographic dataset therefore were included in the study. The demographic and clinical characteristics of the patients are shown in - Table $\mathbf{1}$. Based on the received treatment, the patients were divided into two groups. Group A (treated with SMS) had 42 patients (6 females, 36 males) and group B (treated with SMS and GPRP) had 45 patients (11 females, 34 males). The average follow-up time was 14.4 months $( \pm 6.7)$ in group $A$ and 12.1 $( \pm 5.2)$ in group B. The mean time passed from the trauma

Table 1 Principal demographic and clinical features of patients studied

\begin{tabular}{|c|c|c|}
\hline Demographics & Group A & Group B \\
\hline Number of patients (\%) & $42(48.3)$ & $45(51.7)$ \\
\hline Age $(y)$ & $32.1 \pm 9.1$ & $31.5 \pm 12.3$ \\
\hline Gender & $6 \mathrm{~F}, 36 \mathrm{M}$ & $11 \mathrm{~F}, 34 \mathrm{M}$ \\
\hline BMI & $27.8 \pm 2.1$ & $26.7 \pm 3.8$ \\
\hline \multicolumn{3}{|l|}{ Comorbidity, n (\%) } \\
\hline Smokers & $19(45.2)$ & $24(53.3)$ \\
\hline Diabetes & $1(2.4)$ & - \\
\hline Hypertension & - & $2(4.4)$ \\
\hline $\begin{array}{l}\text { Time between wrist } \\
\text { trauma and surgery }\end{array}$ & $11.2( \pm 5.6) \mathrm{mo}$ & $12.1( \pm 6.2) \mathrm{mo}$ \\
\hline $\begin{array}{l}\text { Previous nonoperative } \\
\text { treatment with long } \\
\text { arm cast }\end{array}$ & $18(42.8)$ & $14(31.1)$ \\
\hline $\begin{array}{l}\text { Misdiagnosed fractures } \\
\text { (not properly treated) }\end{array}$ & $24(57.2)$ & $31(68.9)$ \\
\hline
\end{tabular}

Abbreviations: BMI, body mass index; F, female; M, male. 
clearly referable to the fracture was $11.2( \pm 5.6)$ months. Before undergoing surgical treatment, 18 (42.8\%) patients in group A and 14patients (31.1\%) patients in group B underwent nonoperative treatment with long arm cast for approximately 45 days ( \pm 7.3 ), whereas 24 (57.2\%) patients in group A and 31 (68.9\%) patients in group B were cases of misdiagnosed fractures (not properly treated).

Union was achieved in 40 patients in group A (95.2\%) and in all patients in group $B(100 \%)$. The average healing time after operation was $2.9( \pm 0.9)$ months in group $A$ and 2.1 $( \pm 0.5)$ in group $\mathrm{B}(p=0.03)$. In Group $\mathrm{A}$, the mean MWS was $48.5( \pm 6.3)$ before the surgery, $78.1( \pm 8.9)$ at 3 months, 85.4 $( \pm 5.5)$ at 6 months, and $88.3( \pm 7.8)$ at 12 months. In group B, the mean MWS was $44.8( \pm 8.1)$ before the surgery, 87.4 $( \pm 9.3)$ at 3 months, $91.4( \pm 6.9)$ at 6 months, and $92.1( \pm 7.2)$ at 12 months. A statistically significant difference was noted in the improvement of function in both groups ( $p=0.02$ and 0.002 , respectively). While comparing the two groups, a statistically significant difference was observed only for the value measured three months after surgery $(p=0.04)$. In group A, the QuickDASH score improved from $47.7( \pm 6.2)$ points to $12.6( \pm 3.1)$ points after 3 months, $8.6( \pm 2.7)$ after 6 months, and $7.9( \pm 4.2)$ after 12 months. In Group B, the QuickDASH score improved from $46.2( \pm 6.2)$ points to 7.2 $( \pm 4.6)$ points after 3 months, $6.9( \pm 3.3)$ after 6 months, and $7.2( \pm 1.1)$ after 12 months. Although a statistically significant difference was observed in the reduction of QuickDASH scores in both groups ( $p=0.001$ and 0.002 , respectively), the major difference between the two groups was noted after 3 months of surgery $(p=0.02)$. In group $A$, the mean VAS score at t0 was $5.6( \pm 0.9)$, which decreased to $3.5( \pm 0.7)$ at 3 months, $2.1( \pm 0.4)$ at 6 months, and $1.9( \pm 0.6)$ at 12 months. In group B, the mean VAS score at t0 was $6.1( \pm 1.1)$, which decreased to $1.9( \pm 1.3)$ at 3 months, $1.8( \pm 0.7)$ at 6 months, and $1.5( \pm 0.9)$ at 12 months. The statistically significant difference between the two groups was observed only for the value measured three months after surgery $(p=0.02)$. Results are given in $\boldsymbol{-}$ Table $\mathbf{2}$.

\section{Discussion}

Scaphoid fractures frequently involve young and active adults. ${ }^{17-19}$ Hence, it is desirable to shorten the healing time. Geoghegan et al studied undisplaced scaphoid fractures treated conservatively with forearm cast. They found that fractures that showed to be united on CT images after 4 weeks do not need further immobilization. ${ }^{20}$ Evidence suggests to avoid cast including the thumb in undisplaced and stable fractures. ${ }^{21,22}$ SNUs fixed with SMS are stable and can therefore be compared with undisplaced fractures. ${ }^{23}$ Hence, we decided to perform the immobilization for only 4 weeks after surgery to avoid immobilization overtreatment. In the literature, there is no unique way to define and characterize SNUs. ${ }^{24}$ Age of trauma, and radiological and intraoperative findings are the main parameters to assess nonunions. ${ }^{24,25}$

SNUs are not healed fractures, but living bone alongside the nonunion site preserves its healing capacity. ${ }^{26}$ They have
Table 2 Table showing the main results

\begin{tabular}{|c|c|c|c|}
\hline Variables & Group A & Group B & $p$-Value \\
\hline $\begin{array}{l}\text { Mean healing } \\
\text { time (months) }\end{array}$ & $2.9( \pm 0.9)$ & $2.1( \pm 0.5)$ & 0.03 \\
\hline \multicolumn{4}{|l|}{ Mayo Wrist Score } \\
\hline Preoperative & $48.5( \pm 6.3)$ & $44.8( \pm 8.1)$ & $>0.05$ \\
\hline 3 mo after surgery & $78.1( \pm 8.9)$ & $87.4( \pm 9.3)$ & 0.04 \\
\hline 6 mo after surgery & $85.4( \pm 5.5)$ & $91.4( \pm 6.9)$ & $>0.05$ \\
\hline 12 mo after surgery & $88.3( \pm 7.8)$ & $92.1( \pm 7.2)$ & $>0.05$ \\
\hline \multicolumn{4}{|l|}{ QuickDASH score } \\
\hline Preoperative & $47.7( \pm 6.2)$ & $46.2( \pm 6.2)$ & $>0.05$ \\
\hline 3 mo after surgery & $12.6( \pm 3.1)$ & $7.2( \pm 4.6)$ & 0.02 \\
\hline 6 mo after surgery & $8.6( \pm 2.7)$ & $6.9( \pm 3.3)$ & $>0.05$ \\
\hline 12 mo after surgery & $7.9( \pm 4.2)$ & $7.2( \pm 1.1)$ & $>0.05$ \\
\hline \multicolumn{4}{|l|}{ VAS score } \\
\hline Preoperative & $5.6( \pm 0.9)$ & $6.1( \pm 1.1)$ & $>0.05$ \\
\hline 3 mo after surgery & $3.5( \pm 0.7)$ & $1.9( \pm 1.3)$ & 0.02 \\
\hline 6 mo after surgery & $2.1( \pm 0.4)$ & $1.8( \pm 0.7)$ & $>0.05$ \\
\hline 12 mo after surgery & $1.9( \pm 0.6)$ & $1.5( \pm 0.9)$ & $>0.05$ \\
\hline
\end{tabular}

Abbreviations: DASH, Disabilities of the Arm, Shoulder, and Hand; VAS, visual analog scale.

a lower healing potential compared with simple fractures. ${ }^{27,28}$

Schmidle et al found that the healing capacity depends on the time passed out from trauma concerning the distal pole and gap region; conversely, there is limited healing capacity of the proximal pole already at early stages, with few alterations over time. ${ }^{26}$

Trusting in potential healing, some authors have reported positive results of fixed SNUs without bone grafting. ${ }^{29-31}$ However, these studies are heterogeneous considering the population, techniques, and assessment of results, even if they reported promising results. Only one study described the use of PRP alone in scaphoid fractures. Namazi and Kayedi described intra-articular injection in conservative treated scaphoid fracture (without bone grafting). They prospectively assessed pain reduction and improved function with favorable results. ${ }^{12}$

Our study demonstrates that staple is useful in treating waist SNUs and that GPRP is useful to improve healing, which is in agreement with other studies on bone healing. ${ }^{8-10,12,13}$

A faster and complete recovery leads to a higher wrist and upper limb function, probably because it concurs with a shorter period of immobilization and less work and sport limitation.

GPRP is an autologous, easy-to-produce, cheap, and effective product in our experience (-Figs. 3 and 4 ). Furthermore, the gel can fill very well the gap between the fragments. Given the results, in addition to fixation, since 2018, we routinely applied GPRP in any case of SNU without shortening, without significant bone resorption, avascular necrosis, and deformities. Thus, we use it when bone graft is not strictly needed. ${ }^{6}$ 


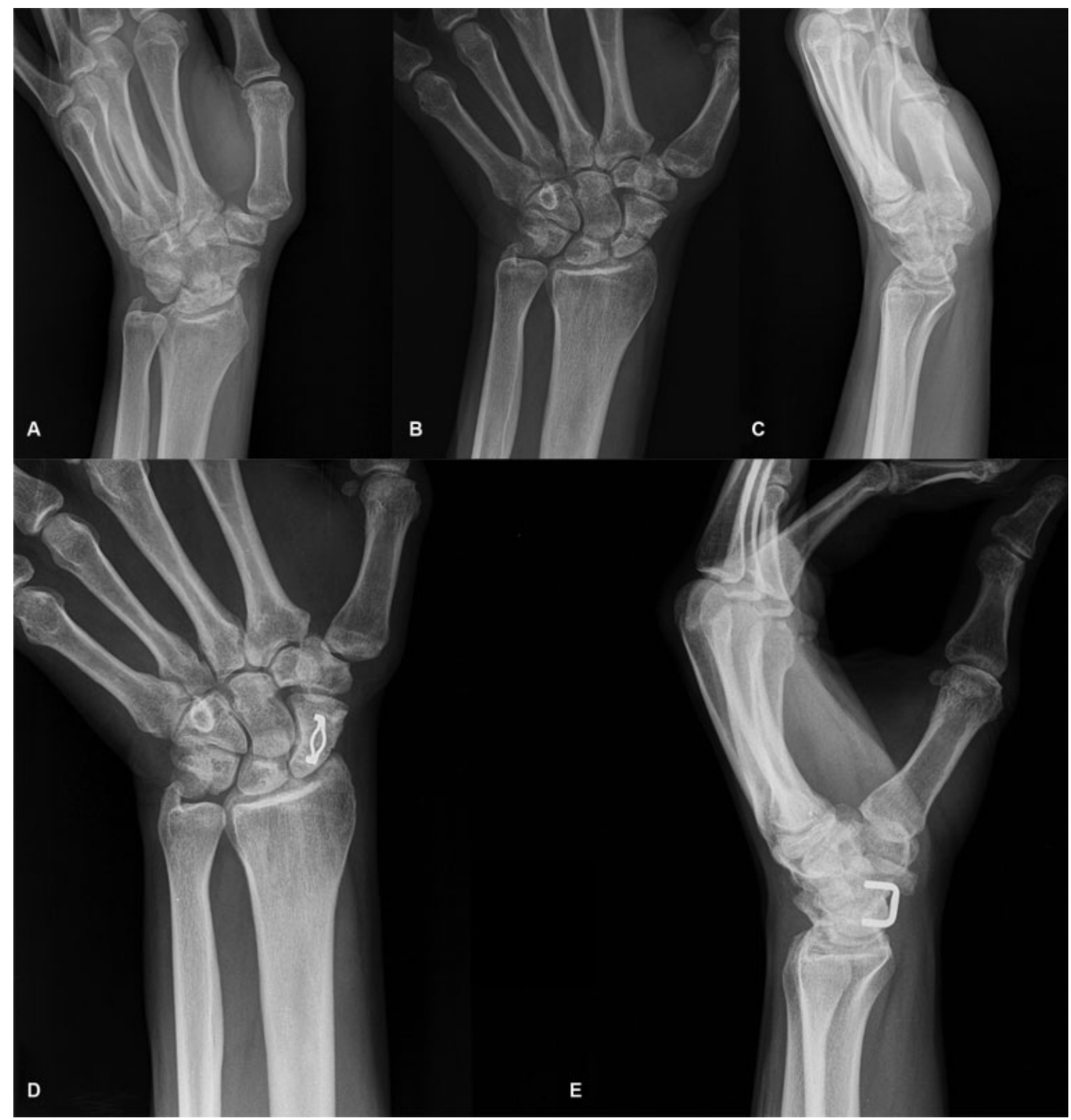

Fig. 3 A 32-year-old male patient with scaphoid nonunion in the left hand, with time passed from trauma of 12 months. (A-C) Preoperative radiographs. (D,E) Postoperative radiographs (2 months after surgery).

The staple gives strong stability and properly compresses the nonunion site.

In our institution, SMS is currently used to fix scaphoid waist fractures. It is effective in compressing the nonunion site and giving stability to the fracture. No one before us has described the use of staple in more than 6 months SNUs, proving that GPRP can improve healing. We hope that our positive results could be useful for further studies. We are not to forget our failures. Two cases of failure happened in group A (staple without GPRP). Both cases were successfully treated again with nonvascularized bone graft. Both cases had a very long duration of nonunion (12 and 15 months), with one of them being a smoker, that is, a known negative prognostic connotation, ${ }^{32}$ but we cannot know clearly why they failed. In fact, we successfully treated patients with a long duration of nonunion and smokers in both groups. However, both patients underwent bone graft surgery later and reached union.

This study has some limitations. It is a retrospective study. We did not perform routine CT scan to confirm healing (except in two cases that were not healed after 3 months), but we assessed healing using a combination of X-rays and clinical findings. We chose to not use postoperative MRI because its sensitivity and specificity to asses healing after a staple application are not clearly known. Conversely, some studies have already been published on scaphoid healing after fixation with titanium screws. ${ }^{33,34}$ We did not routinely use preoperative MRI because avascular necrosis was directly, intraoperatively checked. 


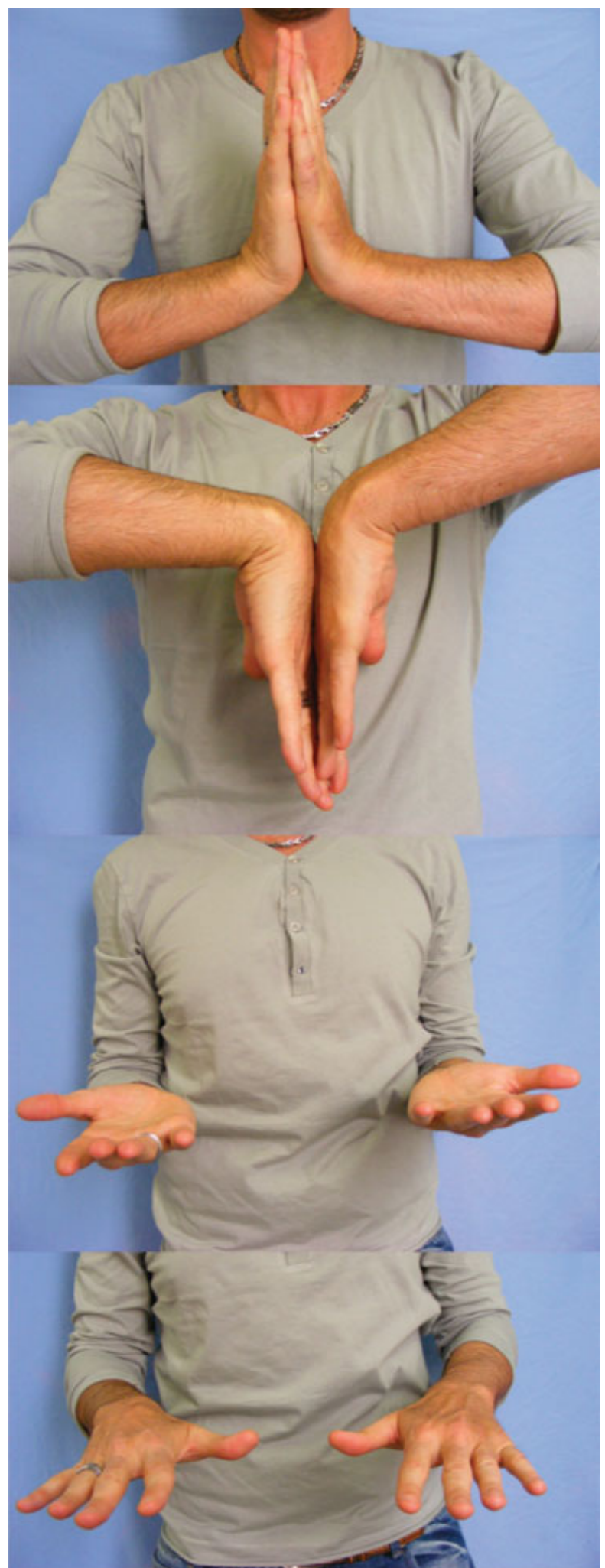

Fig. 4 Clinical results after 2 months (the same patient as in - Fig. $\mathbf{3}$ ).

Further research would therefore be needed considering different hardware, such as a compression screw, with and without PRP, to compare these results.

In conclusion, SMS fixation could be considered a valid treatment in select cases of scaphoid waist nonunions, without bone deformity and/or shortening. GPRP seems to be effective in improving clinical and radiological results.

Conflict of Interest

None declared.

\section{References}

1 Nacif GC, Pedro FMJ, de Moraes VY, Fernandes M, Bellot JC. How scaphoid fractures are treated in Brazil. Acta Ortop Bras 2018;26 (05):290-293

2 Duckworth AD, Jenkins PJ, Aitken SA, Clement ND, Court-Brown CM, McQueen MM. Scaphoid fracture epidemiology. J Trauma Acute Care Surg 2012;72(02):E41-E45

3 Gelberman RH, Menon J. The vascularity of the scaphoid bone. J Hand Surg Am 1980;5(05):508-513

4 Steinmann SP, Adams JE. Scaphoid fractures and nonunions: diagnosis and treatment. J Orthop Sci 2006;11(04):424-431

5 Szabo RM, Manske D. Displaced fractures of the scaphoid. Clin Orthop Relat Res 1988;(230):30-38

6 Hovius SER, de Jong T. Bone grafts for scaphoid nonunion: an overview. Hand Surg 2015;20(02):222-227

7 Luchetti TJ, Rao AJ, Fernandez JJ, Cohen MS, Wysocki RW. Fixation of proximal pole scaphoid nonunion with non-vascularized cancellous autograft. J Hand Surg Eur Vol 2018;43(01):66-72

8 Zhang N, Wu YP, Qian SJ, Teng C, Chen S, Li H. Research progress in the mechanism of effect of PRP in bone deficiency healing. ScientificWorldJournal 2013;2013:134582

9 Acosta-Olivo C, Garza-Borjon A, Simental-Mendia M, VilchezCavazos F, Tamez-Mata Y, Peña-Martinez V. Delayed union of humeral shaft fractures: comparison of autograft with and without platelet-rich plasma treatment: a randomized, single blinded clinical trial. Arch Orthop Trauma Surg 2017;137(09):1247-1252

10 Gianakos A, Zambrana L, Savage-Elliott I, Lane JM, Kennedy JG. Platelet-rich plasma in the animal long-bone model: an analysis of basic science evidence. Orthopedics 2015;38(12):e1079-e1090

11 Wang W, Yeung KWK. Bone grafts and biomaterials substitutes for bone defect repair: a review. Bioact Mater 2017;2(04):224-247

12 Namazi H, Kayedi T. Investigating the effect of intra-articular platelet-rich plasma injection on union: pain and function improvement in patients with scaphoid fracture. J Hand Microsurg 2016;8(03):140-144

13 Passaretti U, Penza A, Fusco M, D’Arienzo A. Il trattamento delle pseudartrosi di scafoide con fattori di crescita. Riv Chir Mano 2006;43(03):258-260

14 Filan SL, Herbert TJ. Herbert screw fixation of scaphoid fractures. J Bone Joint Surg Br 1996;78(04):519-529

15 Krimmer H, Krapohl B, Sauerbier M, Hahn P. Post-traumatic carpal collapse (SLAC- and SNAC-wrist)-stage classification and therapeutic possibilities [in German]. Handchir Mikrochir Plast Chir 1997;29(05):228-233

16 Winkel R, Schlageter M. NITINOL shape memory staple for osteosynthesis of the scaphoid [in German]. Oper Orthop Traumatol 2009;21(4-5):361-372

17 Van Tassel DC, Owens BD, Wolf JM. Incidence estimates and demographics of scaphoid fracture in the U.S. population. J Hand Surg Am 2010;35(08):1242-1245

18 Wolf JM, Dawson L, Mountcastle SB, Owens BD. The incidence of scaphoid fracture in a military population. Injury 2009;40(12): 1316-1319

19 Garala K, Taub NA, Dias JJ. The epidemiology of fractures of the scaphoid: impact of age, gender, deprivation and seasonality. Bone Joint J 2016;98-B(05):654-659

20 Geoghegan JM, Woodruff MJ, Bhatia R, et al. Undisplaced scaphoid waist fractures: is 4 weeks' immobilisation in a below-elbow cast sufficient if a week 4 CT scan suggests fracture union? J Hand Surg Eur Vol 2009;34(05):631-637 
21 Clay NR, Dias JJ, Costigan PS, Gregg PJ, Barton NJ. Need the thumb be immobilised in scaphoid fractures? A randomised prospective trial. J Bone Joint Surg Br 1991;73(05):828-832

22 Dias JJ, Wildin CJ, Bhowal B, Thompson JR. Should acute scaphoid fractures be fixed? A randomized controlled trial. J Bone Joint Surg Am 2005;87(10):2160-2168

23 Dunn J, Kusnezov N, Fares A, Mitchell J, Pirela-Cruz M. The scaphoid staple: a systematic review. Hand (N Y) 2017;12(03): 236-241

24 Ferguson DO, Shanbhag V, Hedley H, Reichert I, Lipscombe S, Davis TRC. Scaphoid fracture non-union: a systematic review of surgical treatment using bone graft. J Hand Surg Eur Vol 2016;41 (05):492-500

25 Corrales LA, Morshed S, Bhandari M, Miclau T III. Variability in the assessment of fracture-healing in orthopaedic trauma studies. J Bone Joint Surg Am 2008;90(09):1862-1868

26 Schmidle G, Ebner HL, Klima G, et al. Time-dependent changes in bone healing capacity of scaphoid fractures and non-unions. J Anat 2018;232(06):908-918

27 Schuind F, Haentjens P, Van Innis F, Vander Maren C, GarciaElias M, Sennwald G. Prognostic factors in the treatment of carpal scaphoid nonunions. J Hand Surg Am 1999;24(04): $761-776$
28 Rein S, Hanisch U, Schaller H-E, Zwipp H, Rammelt S, Weindel S. Evaluation of bone remodeling in regard to the age of scaphoid non-unions. World J Orthop 2016;7(07):418-425

29 Saper D, Shah AK, Stein AB, Jawa A. Screw fixation without bone grafting for delayed unions and nonunions of minimally displaced scaphoids. Am J Orthop 2018;47(08):1-8

30 Slade JF III, Geissler WB, Gutow AP, Merrell GA. Percutaneous internal fixation of selected scaphoid nonunions with an arthroscopically assisted dorsal approach. J Bone Joint Surg Am 2003; 85-A(Suppl 4):20-32

31 Capo JT, Shamian B, Rizzo M. Percutaneous screw fixation without bone grafting of scaphoid non-union. Isr Med Assoc J 2012;14 (12):729-732

32 Little CP, Burston BJ, Hopkinson-Woolley J, Burge P. Failure of surgery for scaphoid non-union is associated with smoking. J Hand Surg $\mathrm{Br}$ 2006;31(03):252-255

33 Ganapathi M, Joseph G, Savage R, Jones AR, Timms B, Lyons K. MRI susceptibility artefacts related to scaphoid screws: the effect of screw type, screw orientation and imaging parameters. J Hand Surg Br 2002;27(02):165-170

34 Ganapathi M, Savage R, Jones AR. MRI assessment of the proximal pole of the scaphoid after internal fixation with a titanium alloy Herbert screw. J Hand Surg Br 2001;26(04):326-329 